\title{
The 2-carbazolylnitrenium ion and its conjugate acid and base forms
}

\author{
Robert A. McClelland* and Victoria E. Licence \\ Department of Chemistry, University of Toronto, Toronto, Ontario M5S 3H6, Canada \\ E-mail: rmcclell@alchemy.chem.utoronto.ca
}

\begin{abstract}
Dedicated to Oswald S. Tee on the occasion of his $60^{\text {th }}$ birthday, and in recognition of his many contributions to chemistry in Canada

(received 12 Aug 01; accepted 06 Nov 01; published on the web 14 Nov 01)
\end{abstract}

\begin{abstract}
The 2-carbazolylnitrenium ion and its 9-methyl analog have been investigated by laser flash photolysis. These electrophiles were generated by irradiation of 2-azido-9H-carbazole and 9methyl-2-azido- $9 H$-carbazole in solutions of $20 \%$ acetonitrile in water. Kinetic and spectral evidence is presented for three forms of the 2-carbazolylnitrenium ion, the monocation, its dication conjugate acid and a neutral quinonoid-like conjugate base obtained by loss of the 9-NH proton. The 9-methyl system, which cannot form the neutral species, exists as dication and monocation. Acidity constants relating the various forms and rate constants for their reaction with water, bromide ion and azide ion are obtained by kinetic analyses.
\end{abstract}

Keywords: Laser flash photolysis, 2-carbazolylnitrenium ion, 2-azido-9H-carbazole

\section{Introduction}

2-Aminofluorene 1 and 2-amino- $\alpha$-carboline 2 are representative members of a diverse group of arylamine carcinogens found, for example, in tobacco smoke, automobile exhaust, broiled meats and fish, and as side products of industrial processing. ${ }^{1}$ The fluorene derivative $\mathbf{1}$ is a carbocyclic example that has seen extensive investigation since its carcinogenic properties were discovered over 50 years ago. ${ }^{2}$ The carboline 2 is one of the more common carcinogenic and mutagenic heterocyclic amines derived from pyrolysis of proteins and amino acids found in cooked food. ${ }^{3}$ A feature common to carbocyclic and heterocyclic amines is a requirement for metabolic activation -oxidation of the arylamine 3 to an arylhydroxylamine $\mathbf{4}$, followed by conversion to an acetate or sulfate ester $5 .{ }^{4}$ While there has been debate over the years, there is now clear evidence with both the carbocyclic and heterocyclic amines that such esters undergo spontaneous $\mathrm{N}-\mathrm{O}$ heterolysis producing an arylnitrenium ion 6 . $^{5,6}$ This reactive cation arylaminates and 
alkylates DNA to produce covalent adducts $^{7}$ that can lead to mutagenesis and carcinogenesis.
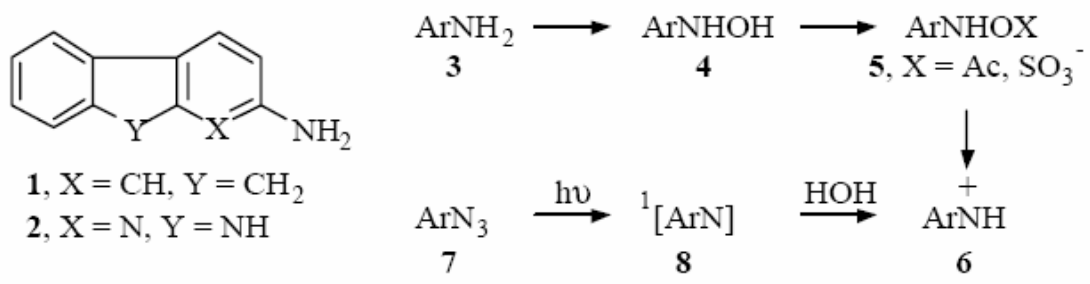

\section{Scheme 1}

Nitrenium ions are a class of reactive electrophiles that, in contrast to carbocations, have not been successfully characterized under superacid conditions. Since 1993 however, there have been a number of reports of their direct observation using laser flash photolysis (LFP). ${ }^{8}$ This approach allows for the their generation in solvents such as acetonitrile and water, and has provided direct kinetic information about the reactivity of nitrenium ions with the solvent and with added nucleophiles. The recent use of $\operatorname{IR}^{9}$ and $\operatorname{Raman}^{10}$ detection systems is also providing detailed structural information. An approach that our group has used is outlined in Scheme $1 .^{6}$ An aryl azide 7 serves as the photochemical precursor. Irradiation produces a reactive singlet nitrene 8 that in aqueous solutions is protonated on the picosecond time scale to provide the conjugate acid, the nitrenium ion $\mathbf{6}$.

This paper provides a kinetic analysis of the behavior of the nitrenium ions $\mathbf{1 1}$ and $\mathbf{1 2}$ obtained, respectively, upon irradiation of 2-azido- $9 H$-carbazole 9 and its 9-methyl analog 10 (Scheme 2). These cations lie intermediate between the carbocyclic 2-fluorenyl nitrenium ion, and the nitrenium ion derived from 2 -amino- $\alpha$-carboline. The former cation has been studied by LFP from the precursor 2-azidofluorene. ${ }^{6}$ The Novak group have recently published a kinetic investigation of the latter using the indirect method of competition kinetics. ${ }^{5 f}$ An attractive feature of the carbazole system is that it provides an evaluation of the role of the central nitrogen. As shown in the resonance contributors $\mathbf{1 1 b}$ and $\mathbf{1 2 b}$, this nitrogen in principle can provide conjugative stabilization to the positive charge. We also anticipated that when $\mathrm{R}=\mathrm{H}$, the proton might be removed to generate a neutral conjugate base. We have recently described neutral conjugate base forms of arylnitrenium ions in the case of benzidine derivatives. ${ }^{11}$

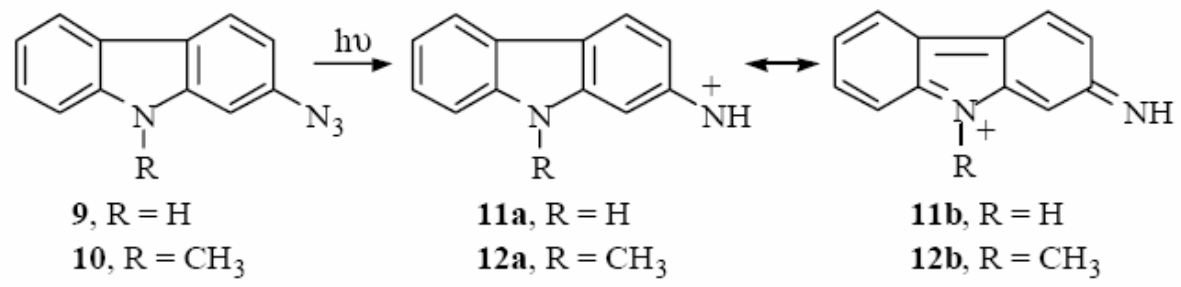

\section{Scheme 2}




\section{Results and Discussion}

The azides 9 and 10 were irradiated with $308 \mathrm{~nm}$ laser light in solutions of $20 \%$ acetonitrile in water. Transient spectra were constructed point-by-point at wavelengths greater than $350 \mathrm{~nm}$ where the azides did not absorb. Figure 1 shows spectra obtained with the methyl derivative 10 in $0.001 \mathrm{M} \mathrm{HClO}_{4}$. The behavior of this azide in $\mathrm{pH} 7$ phosphate buffer was identical. This system is characterized by a relatively intense signal with two maxima. This absorbance decays on the hundreds of microsecond timescale resulting in the spectrum labeled Final(a) in Fig. 1. The absorbance changes follow single exponential kinetics, with the same rate constant over the entire spectral range. Irradiation with bromide present results in more rapid decay, and has the feature that there is less residual absorbance, as shown in the spectrum labeled Final(b).

The NH azide 9 (Figure 2) was found to have essentially the same behavior in $0.001 \mathrm{M}$ $\mathrm{HClO}_{4}$, with very similar spectra and spectral changes, and also similar rate constants for the decay in solvent alone and with bromide present. With this azide however, the transient spectrum in $\mathrm{pH} 7$ phosphate buffer was quite different, with little OD at $440 \mathrm{~nm}$, and a peak with $\lambda_{\max }$ at $360 \mathrm{~nm}$ that underwent a very slow decay. A detailed spectrum was also constructed in $0.1 \mathrm{M}$ $\mathrm{HClO}_{4}$, and was also found to be different. A similar difference between $0.001 \mathrm{M} \mathrm{HClO}_{4}$ and 0.1 $\mathrm{M} \mathrm{HClO}_{4}$ was also apparent with the NMe system.
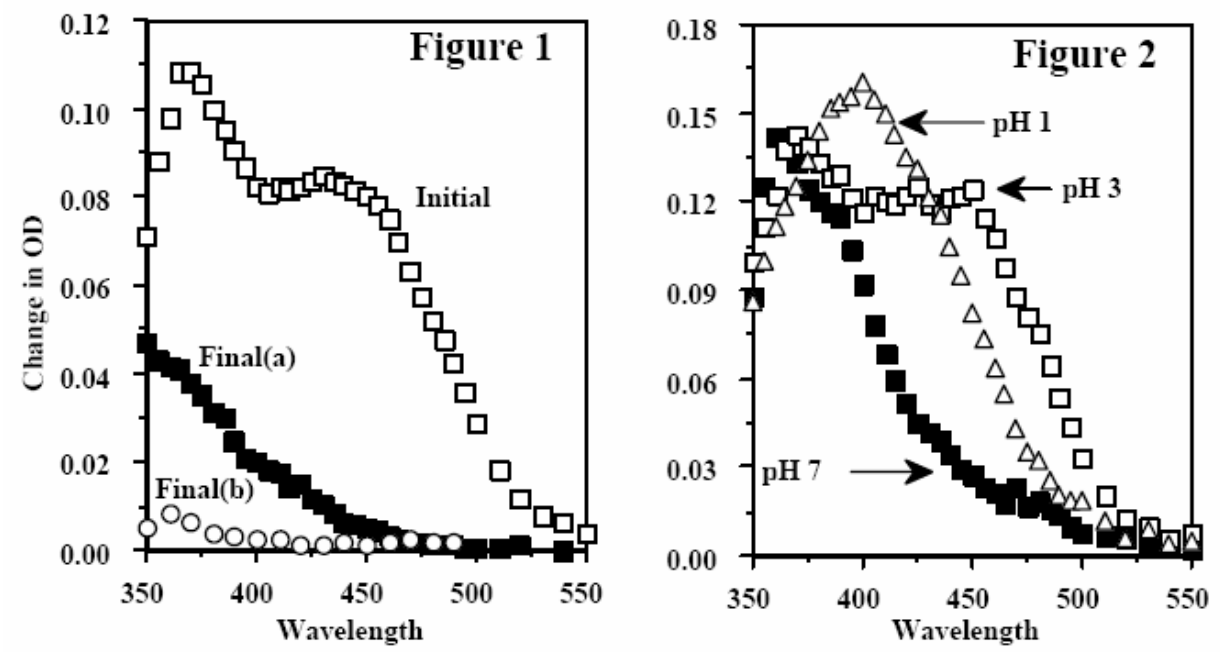

Figures 1 and 2. Transient absorption spectra obtained upon $308 \mathrm{~nm}$ irradiation of 2-azido-9methyl-9H-carbazole (Fig. 1) and 2-azido-9H-carbazole (Fig. 2). Carbazole concentrations were $5 \times 10^{-5} \mathrm{M}$ in $20 \%$ acetonitrile. Fig. 1 was obtained in $0.001 \mathrm{M} \mathrm{HClO}_{4}$. The spectrum labeled "Initial" was obtained $200 \mathrm{~ns}$ after the laser pulse, and the spectrum "Final(a)" at the completion of the exponential decay. The spectrum "Final(b)" was obtained at the completion of the exponential decay with $0.04 \mathrm{M} \mathrm{NaBr}$ present. The spectra in Fig. 2 were the "Initial" spectra obtained $200 \mathrm{~ns}$ after the laser pulse in solutions with the $\mathrm{pH}$ indicated.

The effect of $\mathrm{pH}$ was studied in detail for the NH system. A monitoring wavelength of 450 
$\mathrm{nm}$ was chosen and the initial optical density measured for a series of solutions of 2-azido-9Hcarbazole prepared and irradiated under identical conditions. The results are shown in Figure 3.
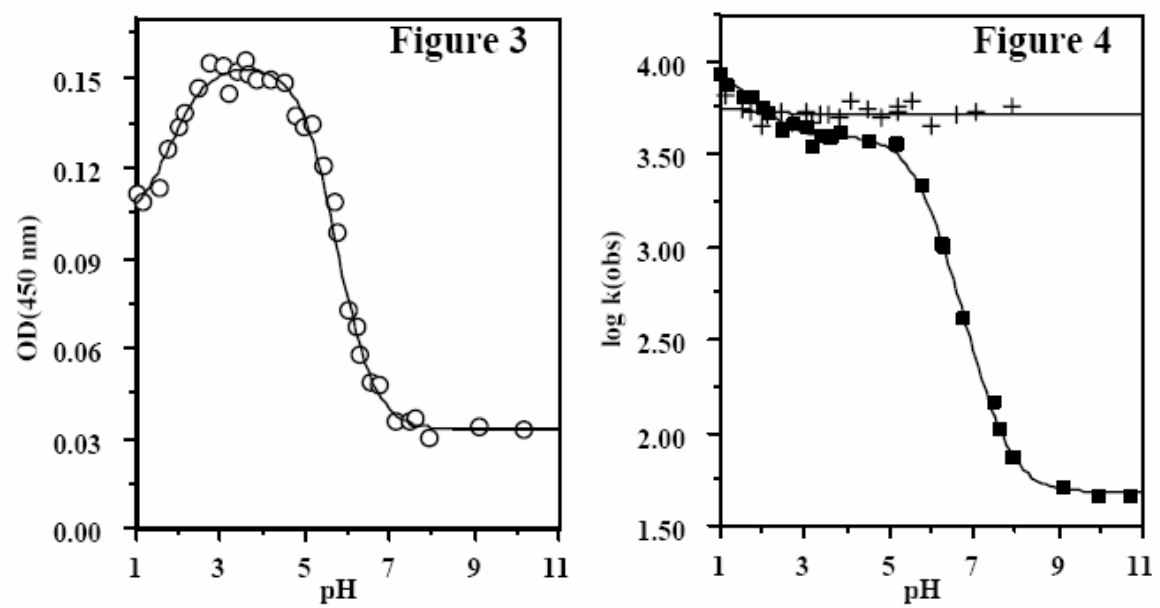

Figures 3 and 4. Behavior of transients as a function of $\mathrm{pH}$. Figure 3 plots the optical density at $450 \mathrm{~nm}$ measured $200 \mathrm{~ns}$ after the laser pulse for solutions of the same concentration of 2-azido$9 \mathrm{H}$-carbazole $\left(5.0 \times 10^{-5} \mathrm{M}\right)$ irradiated at $308 \mathrm{~nm}$ under identical conditions. Figure 4 plots the first-order rate constants for the decay of the transients obtained with 2-azido-9H-carbazole (squares) and 2-azido-9-methyl-9H-carbazole (crosses). Data were obtained in 20\% acetonitrile at $20{ }^{\circ} \mathrm{C}$ and an ionic strength of $0.1 \mathrm{M}$ maintained with sodium perchlorate.

Figure 4 shows the effect of $\mathrm{pH}$ on the rate constants for the decay of the transients in the $20 \%$ acetonitrile solutions. The data for the N-methyl system were obtained by monitoring at 450 $\mathrm{nm}$ throughout. The same wavelength was employed for the $\mathrm{NH}$ system below $\mathrm{pH} 5$, with a monitoring wavelength of $370 \mathrm{~nm}$ above $\mathrm{pH}$ 5. The $\mathrm{pH}$ was maintained with $\mathrm{HClO}_{4}$ (below $\mathrm{pH}$ 3.5) and with acetate, phosphate and carbonate buffers. Dilute buffer solutions were employed; buffer dilutions showed that the buffer had no effect, outside of the experimental error of the measurement. The rate constants for the N-methyl system were essentially unchanged from $\mathrm{pH} 1$ to $\mathrm{pH}$ 8. The $\mathrm{NH}$ system showed a small dependence below $\mathrm{pH} 2$, with a significant decrease in rate constant above $\mathrm{pH}$ 6. Rate constants above this $\mathrm{pH}$ were in fact measured with a lamp flash photolysis apparatus. Two other observations were that the decays followed single exponential kinetics throughout and the rate constants did not depend upon the concentration of the precursor.

Both bromide and azide (as their sodium salts) provided significant accelerations of the decay, with the observed rate constants linear in the concentration of the added salt. Secondorder rate constants were obtained as the slopes of such plots for 4-5 different concentrations. These data are plotted as a function of $\mathrm{pH}$ in Figures 5 and 6. 

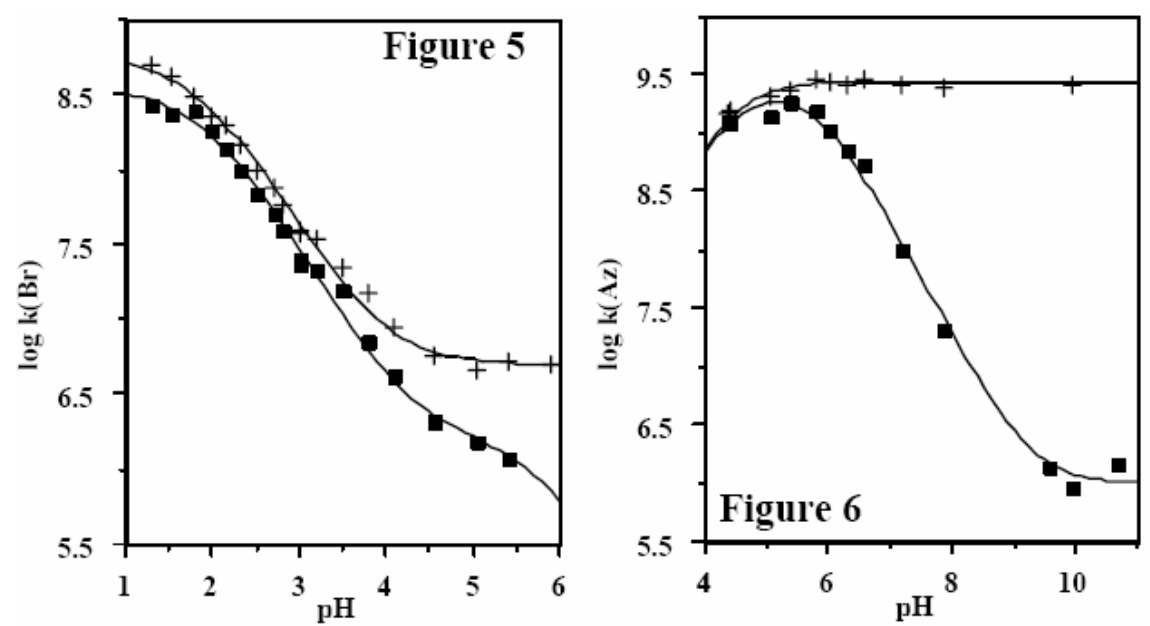

Figures 5 and 6. Second-order rate constants for quenching by bromide ion (Fig. 5) and azide ion (Fig. 6) of the transients obtained with 2-azido-9H-carbazole (squares) and 2-azido-9-methyl$9 \mathrm{H}$-carbazole (crosses). Data were obtained in $20 \%$ acetonitrile at $20{ }^{\circ} \mathrm{C}$ and an ionic strength of $0.1 \mathrm{M}$ maintained with sodium perchlorate.

The quenching by the nucleophiles bromide and azide support the conclusion that the 2azidocarbazoles $\mathbf{9}$ and $\mathbf{1 0}$ are undergoing photochemistry similar to that observed with 2azidofluorene, ${ }^{6 \mathrm{~b}, 10}$ with the nitrenes protonating in $20 \%$ acetonitrile. The spectral behavior, and the dependence on $\mathrm{pH}$ are also consistent with this idea. While nitrenium ions $\mathbf{1 1}$ and $\mathbf{1 2}$ will be the initial intermediate, the kinetic and spectral data require a more complex system. As shown in Scheme 3, there is evidence of an acid-base equilibrium between the cations 11 and 12 and their conjugate acid dications 13 and 14 respectively. With the NH system, there is a second acid-base equilibrium involving a neutral compound 15. All the species in principal can react with water and with the added nucleophiles, although it turns out that not all rate constants can be determined.

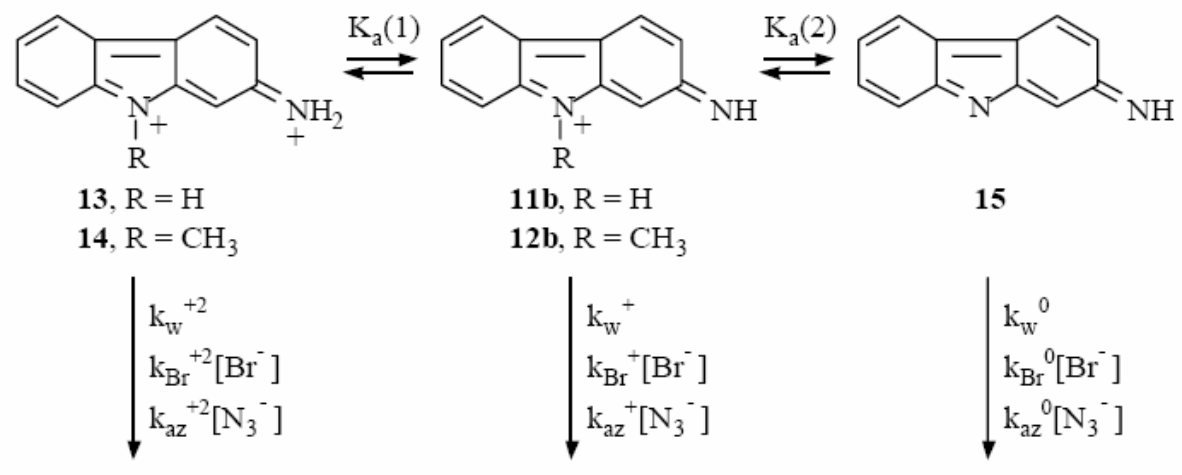

\section{Scheme 3}

Based upon Scheme 3, the observed rate constants for each nucleophile take the form of 
equations 1 and 2, where $\mathrm{Nu}$ refers to $\mathrm{w}, \mathrm{Br}$ or az.For the solvent reaction (Fig. 4), one feature is that there is not much difference between $\mathrm{kw}^{+2}$ and $\mathrm{kw}^{+}$. In fact with the NMe system there is hardly any change between acid and neutral solution, and the presence of the dication is only deduced because of a spectral change and in particular because of the kinetic behavior with bromide (see below). The line drawn in Fig. 4 for NMe is based on a fit to eq 1 setting $\mathrm{Ka}(1)$ at the value determined from the bromide data.

This gave rate constants of $\mathrm{k}^{+2}(\mathrm{w})=(5.7 \pm 0.4) \times 10^{3} \mathrm{~s}^{-1}$ and $\mathrm{k}^{+}(\mathrm{w})=(5.1 \pm 0.3) \times 10^{3} \mathrm{~s}^{-1}$, i.e. the same within experimental error. With NH there is a slight rate increase in acids suggestive of the dication presence. There is a bigger change between $\mathrm{pH} 4$ and $\mathrm{pH}$ 8. Fitting the $\mathrm{NH}$ data to eq 2 gives $\mathrm{kw}^{+2}=(8.9 \pm 0.9) \times 10^{3} \mathrm{~s}^{-1}, \mathrm{kw}^{+}=(4.0 \pm 0.1) \times 10^{3} \mathrm{~s}^{-1}, \mathrm{kw}^{0}=(4.7 \pm 0.4) \times 10^{1} \mathrm{~s}^{-1}, \mathrm{pKa}(1)=$ $1.7 \pm 0.3$ and $\mathrm{pKa}(2)=5.79 \pm 0.04$. Because the change in acids is only small, there is a considerable uncertainty in $\mathrm{pKa}(1)$.

$$
\begin{gathered}
\mathrm{k}(\mathrm{NMe})=\frac{\mathrm{kNu}^{+2} \cdot\left[\mathrm{H}^{+}\right]+\mathrm{k}_{\mathrm{Nu}}^{+} \cdot \mathrm{K}_{\mathrm{a}}(1)}{\left[\mathrm{H}^{+}\right]+\mathrm{K}_{\mathrm{a}}(1)} \\
\mathrm{k}(\mathrm{NH})=\frac{\mathrm{k}_{\mathrm{Nu}}+2 \cdot\left[\mathrm{H}^{+}\right]^{2}+\mathrm{k}_{\mathrm{Nu}}{ }^{+} \cdot \mathrm{K}_{\mathrm{a}}(1) \cdot\left[\mathrm{H}^{+}\right]+\mathrm{k}_{\mathrm{Nu}} 0 \cdot \mathrm{K}_{\mathrm{a}}(1) \cdot \mathrm{K}_{\mathrm{a}}(2)}{\left[\mathrm{H}^{+}\right]^{2}+\mathrm{K}_{\mathrm{a}}(1) \cdot\left[\mathrm{H}^{+}\right]+\mathrm{K}_{\mathrm{a}}(1) \cdot \mathrm{K}_{\mathrm{a}}(2)}
\end{gathered}
$$

Eqn 1

Eqn. 2

The $\mathrm{pKa}$ values for the $\mathrm{NH}$ system can be compared with ones calculated from the absorbance data shown in Fig. 3. Eq 3 applies in this case, where OD(13), OD(11) and OD(15) are the optical densities for the dication, cation and neutral forms under the conditions of this experiment. The line drawn in Fig. 3 is based on a fit to this equation. The acidity constants obtained in this fit were $\mathrm{pKa}(1)=1.8 \pm 0.2$ and $\mathrm{pKa}(2)=5.74 \pm 0.08$, in good agreement with values from the kinetic analysis.

$$
\mathrm{OD}(\mathrm{obs})=\frac{\mathrm{OD}(\mathbf{1 3}) \cdot\left[\mathrm{H}^{+}\right]^{2}+\mathrm{OD}(\mathbf{1 1}) \cdot \mathrm{K}_{\mathrm{a}}(1) \cdot\left[\mathrm{H}^{+}\right]+\mathrm{OD}(\mathbf{1 5}) \cdot \mathrm{K}_{\mathrm{a}}(1) \cdot \mathrm{K}_{\mathrm{a}}(2)}{\left[\mathrm{H}^{+}\right]^{2}+\mathrm{K}_{\mathrm{a}}(1) \cdot\left[\mathrm{H}^{+}\right]+\mathrm{K}_{\mathrm{a}}(1) \cdot \mathrm{K}_{\mathrm{a}}(2)}
$$

Eqn. 3

Quenching by bromide could only be observed in solutions with a $\mathrm{pH}$ less than 5.5-6. At this point the kinetic traces began taking the form of a double exponential, and by $\mathrm{pH} 8$, no quenching occurred. One interpretation is that bromide adds reversibly. ${ }^{12}$ The $\mathrm{pH}$ dependence can be explained by a mechanism involving conjugate acid-base forms of the initial bromide adduct, as shown in Scheme 4 where the position of bromide attachment is based on results in the carboline system. ${ }^{5 \mathrm{f}}$ The formation of the protonated adduct $\mathbf{1 7}$ under acidic conditions would shift the equilibrium to the adduct side (and also provide for rapid rearomatization). 


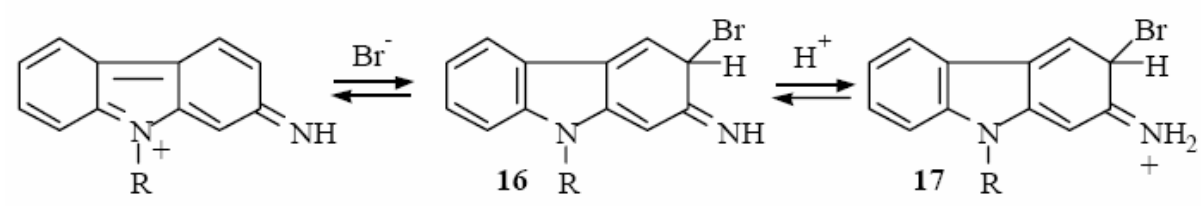

\section{Scheme 4}

The rate constants for bromide (Figure 5) provide a clear indication of the presence of the dication and monocation reacting forms, with a significant difference in reactivity between the two. The data for the NMe compound were fit to eq 1 to give $\mathrm{k}_{\mathrm{Br}+2}=(5.9 \pm 0.5) \times 10^{8} \mathrm{M}^{-1} \mathrm{~s}^{-1}, \mathrm{k}_{\mathrm{Br}+}$ $=(5.0 \pm 0.2) \times 10^{6} \mathrm{M}^{-1} \mathrm{~s}^{-1}$ and $\mathrm{pK}_{\mathrm{a}}(1)=1.85 \pm 0.05$. For the $\mathrm{NH}$ compound, the data were fit to eq 2 with $\mathrm{pKa}(2)$ set to 5.77 , the average of the values determined above, and with $\mathrm{kBr}^{0}$ ignored since the data do not extend to a region where this is important. The fit provided $\mathrm{k}_{\mathrm{Br}+2}=(3.6 \pm 0.2) \mathrm{x}$ $10^{8} \mathrm{M}^{-1} \mathrm{~s}^{-1}, \mathrm{k}_{\mathrm{Br}+}=(1.6 \pm 0.1) \times 10^{6} \mathrm{M}^{-1} \mathrm{~s}^{-1}$ and $\mathrm{pK}_{\mathrm{a}}(1)=1.92 \pm 0.05$. The value of $\mathrm{pK}_{\mathrm{a}}(1)$, which is most precisely determined from the bromide data, is in good agreement with the less precise values calculated from the water rate constants and the spectral data. It can be seen both in Figure 5 and in the rate constants and $\mathrm{pKa}$ values that there is a close similarity between the $\mathrm{NMe}$ and $\mathrm{NH}$ systems.

Azide ion proves to be a very efficient quencher for both the NMe and NH systems. The data for the NMe compound show a plateau at higher $\mathrm{pH}$ with a downward break below $\mathrm{pH} 5$. This can be explained by reaction of the azide ion with the monocation 12, with the downward break below $\mathrm{pH} 5$ associated with protonation of the nucleophile. We have previously measured a $\mathrm{pKa}(\mathrm{HN} 3)$ of 4.46 in $20 \%$ acetonitrile, ionic strength $0.1 \mathrm{M}^{13}$ The curve drawn for the NMe compound in Fig. 6 is based upon a correction of the observed rate constants based on this pKa; the rate constant for $\mathrm{kaz}^{+}$is calculated as $(2.8 \pm 0.2) \times 10^{9} \mathrm{M}^{-1} \mathrm{~s}^{-1}$. The data for the NH compound parallels that of the $\mathrm{NMe}$ in the acidic region ( $\mathrm{pH}$ 4.5-5.5), but there is then a significant decrease in rate constant, with a plateau in base at a much lower level. This again indicates the difference between the $\mathrm{NMe}$ and $\mathrm{NH}$ associated with the ionization of the latter to the neutral 15. With the correction for the azide protonation, the data were fit to give $\mathrm{k}_{\mathrm{az}+}=(2.7 \pm 0.2) \times 10^{9} \mathrm{M}^{-1} \mathrm{~s}^{1}, \mathrm{k}_{\mathrm{az} 0}=$ $(1.0 \pm 0.2) \times 10^{6} \mathrm{M}^{-1} \mathrm{~s}^{-1}$ and a $\mathrm{pKa}(2)$ of $5.83 \pm 0.08$ in good agreement with values obtained in previous analyses. It can be noted that a contribution from reaction of azide ion and the dication was ignored in both the NMe and NH analyses. This can be done because even in the most acidic solution there is less than $1 \%$ of the dication present and the monocation forms are very reactive. In fact the two rate constants for $\mathrm{k}_{\mathrm{az}}{ }^{+}$are close to the diffusion limit of $5 \times 10^{9} \mathrm{M}^{-1} \mathrm{~s}^{-1}$ found for the combination of azide ion and arylnitrenium ions under conditions of ionic strength $0.1 \mathrm{M}$ in $20 \%$ acetonitrile. ${ }^{6 \mathrm{~b}}$ That the values are slightly smaller is consistent with the kinetic stability of 11 and 12. With water rate constants of $4 \times 10^{3}$ and $5 \times 10^{3} \mathrm{~s}^{-1}$, they lie intermediate between the 2fluorenylnitrenium ion, ${ }^{6 \mathrm{~b}} \mathrm{k}_{\mathrm{w}}=2 \times 10^{4} \mathrm{~s}^{-1}$ and the $4^{\prime}$-methoxybiphenylylnitrenium ion, ${ }^{6 \mathrm{c}} \mathrm{k}_{\mathrm{w}}=1 \mathrm{x}$ $10^{3} \mathrm{~s}^{-1}$. It is in this region of reactivity that the azide-nitrenium combination is changing from diffusion control to activation controlled. ${ }^{6 \mathrm{~d}}$

It is now clear that arylnitrenium intermediates have a rich acid-base chemistry. They can be 
protonated on the formal $\mathrm{N}^{+}$center under acidic conditions to give arylamine dications. In cases where there is a conjugating $\mathrm{NH}$ group, loss of the proton can occur to give a quinonoid-type neutral conjugate base. Table 1 provides a comparison of the results for the 2carbazolylnitrenium ion with those previously obtained for the 2fluorenylnitrenium ion, the 2- $(\alpha-$ carbolinyl)nitrenium ion and the very stable nitrenium ion derived from benzidine. In a comparison with the fluorene derivative, it can be seen that the introduction of the central $\mathrm{NH}$ group in the carbazole has had little effect on the lifetime of the nitrenium monocation form $\left(\mathrm{kw}^{+}\right)$. However, as seen in the values for $\mathrm{pK}_{\mathrm{a}}(1)$, the basicity is increased by $1.3 \log$ units. Moreover the carbazole dication is over 200-fold longer lived $\left(\mathrm{k}_{\mathrm{w}}{ }^{+2}\right)$. This is likely a reflection of the ability to place the two positive charges on the two nitrogen atoms, as shown in structure 13. Comparing the carbazole and carboline system, one sees that the introduction of the pyridine nitrogen in the latter has significantly destabilized the monocation. This is particularly apparent in the $\mathrm{pK}_{\mathrm{a}}(2)$ values, which differ by almost three $\log$ units. Not surprisingly the carboline system showed no evidence for the dication. The benzidine cations are much more stable. This is seen in both the $\mathrm{pKa}$ values and the lifetimes. One interesting feature of the comparison with the carbazole is that there is the same difference, a factor of 4 , between $\mathrm{pK}_{\mathrm{a}}(1)$ and $\mathrm{pK}_{\mathrm{a}}(2)$. In other words, in both systems, there is only a region of about $4 \mathrm{pH}$ units where the nitrenium monocation structure predominates. As noted before, ${ }^{1 \mathrm{~b}}$ the benzidine dication is considerably less reactive towards water than the monocation. The opposite is true in the fluorene system. We would argue that the carbazole derivatives are just at the changeover, and thus $\mathrm{k}_{\mathrm{W}}{ }^{+2}$ and $\mathrm{k}_{\mathrm{w}}{ }^{+}$are very similar.

Table 1. Nitrenium ion acidity constants and rate constants for water addition ${ }^{\mathrm{a}}$

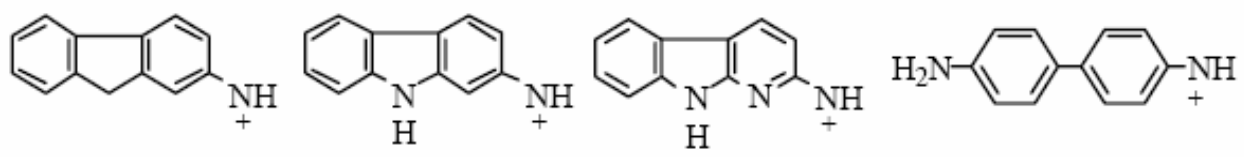

\begin{tabular}{ccccc}
\hline $\mathrm{pK}_{\mathrm{a}}(1)$ & 0.6 & 1.9 & & 5.1 \\
$\mathrm{pKa}(2)$ & - & 5.8 & 3.0 & 9.1 \\
$\mathrm{k}_{\mathrm{w}}{ }^{+2}, \mathrm{~s}^{-1}$ & $1.9 \times 10^{6}$ & $8.9 \times 10^{3}$ & - & $8 \times 10-5$ \\
$\mathrm{k}_{\mathrm{w}}{ }^{+}, \mathrm{s}^{-1}$ & $1.3 \times 10^{4}$ & $4.0 \times 10^{3}$ & $1.4 \times 10^{5}$ & $1 \times 10^{-2}$ \\
$\mathrm{k}_{\mathrm{w}}{ }^{0}, \mathrm{~s}^{-1}$ & - & $4.7 \times 10^{1}$ & $1.7 \times 10^{3}$ & - \\
\hline
\end{tabular}

a Data for fluorenyl are in 20\% acetonitrile, ionic strength $1.0 \mathrm{M}$ (from ref. 6b). Data for carbazolyl 20\% acetonitrile, ionic strength $0.1 \mathrm{M}$ (this work). Data for carbolinyl 20\% acetonitrile, ionic strength $0.5 \mathrm{M}$ (from ref. $5 \mathrm{f}$ ). Data for benzidine derivative in water, at zero (low) ionic strength (from ref. 11b). 


\section{Experimental Section}

General Procedures. The details of the flash photolysis experiments have been published previously. ${ }^{6}$

2-Amino-9H-carbazole, prepared following literature methods, ${ }^{14,15}$ was dissolved in $100 \mathrm{mls}$ of ethanol, and after treatment with concentrated sulfuric acid $(5.0 \mathrm{ml})$ with cooling in ice-water bath, amyl nitrite $(6.0 \mathrm{ml})$ was added in small portions. The reaction mixture was stirred for 20 $\min$ at $35-40{ }^{\circ} \mathrm{C}$. The aryldiazonium salt was precipitated by diluting the reaction mixture with ether $(200 \mathrm{ml})$, the resultant precipitate being washed repeatedly with ether until the ethereal washings gave no coloration. The precipitate was then treated at $0{ }^{\circ} \mathrm{C}$ with a saturated solution of sodium azide $(5.0 \mathrm{~g})$ and sodium acetate $(10 \mathrm{~g})$. After stirring the reaction mixture for $1 \mathrm{~h}$ at room temperature, the product was extracted into ether, which was washed with water, $2.5 \%$ sulfuric acid, water, $10 \%$ sodium hydroxide and finally with water. The ethereal extract was dried over magnesium sulfate and the solvent was evaporated under reduced pressure. The solid so obtained was recrystallized from ethanol: water to give 2-azido-9H-carbazole, mp $180-182{ }^{\circ} \mathrm{C}$, ${ }^{1} \mathrm{H}$ NMR (DMSO-d $\left.{ }^{6}\right) \delta 6.92(\mathrm{~d}, 1 \mathrm{H}), 7.15-7.25(\mathrm{~m}, 2 \mathrm{H}), 7.37(\mathrm{t}, 1 \mathrm{H}), 7.45(\mathrm{~d}, 1 \mathrm{H}), 8.09(\mathrm{~d}, 1 \mathrm{H})$, 8.13 (d, 1H), 11.38 (broad s, $1 \mathrm{H})$; MS m/z $208\left(\mathrm{M}^{+}, 7 \%\right), 180\left(\mathrm{M}^{+}-\mathrm{N}_{2}, 100 \%\right)$; HRMS, calcd for $\mathrm{C}_{12} \mathrm{H}_{8} \mathrm{~N}_{4}, 208.0749$; found 208.0757.

To a solution of this azide $(1.0 \mathrm{mmol})$ and methyl iodide $(1.2 \mathrm{mmol})$ in anhydrous DMSO $(20 \mathrm{ml})$ was added sodium hydride $(95 \%, 1.2 \mathrm{mmol})$. The mixture was stirred under argon for $1 \mathrm{~h}$ at room temperature. The reaction mixture was diluted with ether $(50 \mathrm{ml})$ and the organic layer was washed with water, dried over magnesium sulfate and evaporated. The solid was recrystallized from ethanol: water to give 9-methyl-2-azido-9H-carbazole, mp 101-102 ${ }^{\circ} \mathrm{C},{ }^{1} \mathrm{H}$ NMR (DMSO-d $\left.{ }^{6}\right) \delta 3.80(\mathrm{~s}, 3 \mathrm{H}), 6.9-7.0(\mathrm{~m}, 2 \mathrm{H}), 7.25(\mathrm{t}, 1 \mathrm{H}), 7.38(\mathrm{~d}, 1 \mathrm{H}), 7.45(\mathrm{t}, 1 \mathrm{H}), 8.01$ $(\mathrm{d}, 1 \mathrm{H}), 8.15(\mathrm{~d}, 1 \mathrm{H}) ; \mathrm{MS} \mathrm{m} / \mathrm{z} 222\left(\mathrm{M}^{+}, 6 \%\right), 194\left(\mathrm{M}^{+}-\mathrm{N}_{2}, 100 \%\right)$; HRMS, calcd for $\mathrm{C}_{13} \mathrm{H}_{10} \mathrm{~N}_{4}$, 222.0905; found 222.0906.

\section{Acknowledgements}

Financial support from the Natural Sciences and Engineering Research Council of Canada is gratefully acknowledged.

\section{References}

1. (a) Sugimura, T. Science 1992, 258, 603. Vineis, P. Environ. Health Perspect. 1994, 102, 7. Layton, D. W.; Bogen, K. T.; Knize, M. G.; Hatch, F. T.; Johnson, V. M.; Felton, J. S. Carcinogenesis 1995, 16, 35. 
2. (a) Beland, F. A.; Kadlubar, F. F. In Handbook of Experimental Pharmacology. (b) Cooper, C. S.; Grover, P. L., Eds.; Springer-Verlag: Heidelberg, 1990; Vol. 94/I, pp 267-325. (c) Patel, D. J.; Mao, B.; Gu, Z.; Hingerty, B. E.; Gorin, A.; Basu, A. K.; Broyde, S. Chem. Res. Toxicol. 1998, 11, 391.

3. (a) Eisenbrand, G.; Tang, W. Toxicology 1993, 84, 1. (b) Hatch, F. T.; Knize, M. G.; Felton, J. S. Environ. Mol. Mutagen 1991, 17, 4. (c) Sugimura, T. Environ. Health Perspect. 1986, 67,5 .

4. Raza, H.; King, R. S.; Squires, R. B.; Guengerich, F. P.; Miller, D. W.; Freeman, J. P.; Lang, N. P.; Kadlubar, F. F. Drug Metab. Dispos. 1996, 24, 385.

5. (a) Novak, M.; Kahley, M. J.; Eiger, E.; Helmick, J. S.; Peters, H. E. J. Am. Chem. Soc. 1993, 115, 9453. (b) Novak, M.; Kahley, M. J.; Lin, J.; Kennedy, S. A.; Swanegan, L. A. J. Am. Chem. Soc. 1994, 116, 11626. (c) Novak, M.; Kennedy, S. A. J. Am. Chem. Soc. 1995, 117, 574. (d) Kennedy, S. A.; Novak, M.; Kolb, B. A. J. Am. Chem. Soc. 1997, 119, 7654. (e) Novak, M.; Xu, L; Wolf, R. A. J. Am. Chem. Soc. 1998, 120, 1643. (f) Novak, M.; Kazerani, S. J. Am. Chem. Soc. 2000, 122, 3606.

6. (a) McClelland, R. A.; Davidse, P. A.; Hadzialic, G. J. Am. Chem. Soc. 1995, 117, 4173. (b) McClelland, R. A.; Kahley, M. J.; Davidse, P. A.; Hadzialic, G. J. Am. Chem. Soc. 1996, 118, 4794. (c) Ren, D.; McClelland, R. A. Can. J. Chem. 1998, 76, 78. (d) McClelland, R. A.; Gadosy, T. A.; Ren, D. Can. J. Chem. 1998, 76, 1327. (e) McClelland, R. A.; Ahmad, A.; Dicks, A. P.; Licence, V. E. J. Am. Chem. Soc. 1999, 121, 3303.

7. Dipple, A. Carcinogenesis 1995, 16, 437.

8. Falvey, D. E. Supramol. Photochem. 2000, 6, 249.

9. Srivastava, S.; Ruane, P. H.; Toscano, J. P.; Sullivan, M. B.; Cramer, C. J.; Chiapperino, D.; Reed, E. C.; Falvey, D. E. J. Am. Chem. Soc. 2000, 122, 8271.

10. 10) Zhu, P.; Ong, S. Y.; Chan, P. Y.; Leung, K. H.; Phillips, D. L. J. Am. Chem. Soc. 2001, $123,2645$.

11. (a) Dicks, A. P; Ahmad, A.; McClelland, R. A. Tautomers and Conjugate Base of the Nitrenium Ion Derived from $N$-Acetylbenzidine, J. Chem. Soc., Perkin Trans. 2 1999, (b) McClelland, R. A.; Ren, D.; D'Sa, R.; A. R. Ahmed, A. R. Can. J. Chem. 2000, 78, 1178.

12. McClelland, R. A.; Banait, N.; Steenken, S. J. Am. Chem. Soc. 1986, 108, 7023.

13. McClelland, R. A.; Ren, D.; Ghobrial, D.; Gadosy, T. A. J. Chem. Soc., Perkin Trans. 2 1997, 451.

14. Mendenhall, G. D.; Smith, P. A. S. Org. Syn. 1966, 46, 84.

15. Sawicki, E. J. Am. Chem. Soc. 1954, 76, 664. 